\title{
Health impact assessment of air pollution in Shiraz, Iran: a two-part study
}

\author{
Ehsan Gharehchahi ${ }^{1}$, Amir Hossein Mahvi ${ }^{1,2}$, Hassan Amini ${ }^{3 *}$, Ramin Nabizadeh ${ }^{1}$, Ali Asghar Akhlaghi ${ }^{4,5}$, \\ Mansour Shamsipour ${ }^{4,6}$ and Masud Yunesian ${ }^{1,7^{*}}$
}

\begin{abstract}
We aimed to assess health-impacts of short-term exposure to the air pollutants including $\mathrm{PM}_{10}, \mathrm{SO}_{2}$, and $\mathrm{NO}_{2}$ in Shiraz, Iran in a two-part study from 2008 to 2010. In part I, local relative risks (RRs) and baseline incidences (Bls) were calculate using generalized additive models. In part II, we estimated the number of excess hospitalizations (NEHs) due to cardiovascular diseases (CDs), respiratory diseases (RDs), respiratory diseases in elderly group (RDsE-people older than 65 years old), and chronic obstructive pulmonary diseases (COPDs) as a result of exposure to air pollutants using AirQ model, which is proposed approach for air pollution health impact assessment by World Health Organization. In part I, exposure to increase in daily mean concentration of $\mathrm{PM}_{10}$ was associated with hospitalizations due to RDs with a RR of 1.0049 [95\% confidence interval (CI), 1.0004 to 1.0110]. In addition, exposure to increase in daily mean concentration of $\mathrm{SO}_{2}$ and $\mathrm{NO}_{2}$ were associated with hospitalizations due to RDsE and COPDs with RRs of 1.0540 [95\% Cl, 1.0050 to 1.1200], 1.0950 [95\% Cl, 1.0700 to 1.1100$], 1.0280$ [95\% Cl, 1.0110 to 1.0450 ] and 1.0360 [95\% Cl, 1.0210 to 1.0510$]$ per $10 \mu \mathrm{g} / \mathrm{m}^{3}$ rise of these pollutants, respectively. In part II, the maximum NEHs due to CDs because of exposure to $\mathrm{PM}_{10}$ were in 2009-1489 excess cases (ECs). The maximum NEHs due to RDs because of exposure to $\mathrm{PM}_{10}$ were in 2009-1163 ECs. Meanwhile, the maximum NEHs due to RDsE and COPDs because of exposure to $\mathrm{SO}_{2}$ were in 2008, which are 520 and 900 ECs, respectively. In conclusion, elevated morbidity risks were found from acute exposure to air pollutants.
\end{abstract}

Keywords: Air Pollution, AirQ, Cardiovascular Diseases, COPD, Excess Hospitalizations, Health Impact Assessment, Iran, Particulate Matter, Respiratory, Shiraz

\section{Introduction}

Cardiovascular and respiratory diseases, such as chronic obstructive pulmonary diseases (COPDs), are one of the leading causes of mortality and disease burden (e.g., disability-adjusted life years (DALYs)), globally [1,2]. They are increasingly worldwide most prevalent health problems and albeit variety of risk factors have been recognized and introduced as the most common causes of commence or exacerbation, the role of air pollution is irrefutable [3-5]. In fact, many time-series and case-crossover studies [6-14] have demonstrated the contribution of air pollutants in hospitalizations, morbidities, and mortalities (i.e., years of

\footnotetext{
* Correspondence: amini_h@razi.tums.ac.ir; yunesian@tums.ac.ir

${ }^{3}$ Kurdistan Environmental Health Research Center, Kurdistan University of Medical Sciences, Sanandaj, Iran

${ }^{1}$ Department of Environmental Health Engineering, School of Public Health, Tehran University of Medical Sciences, Tehran, Iran

Full list of author information is available at the end of the article
}

life lost-YLL) due to cardiopulmonary diseases, which have been approved by large prospective cohort studies $[15,16]$. With these as backdrop, the importance of health impact assessment (HIA) of air pollutants in local-scales is obvious to quantify these health impacts, and to develop successful and effective management schemes to reduce YLL and years of life disabled (YLD) -DALYs.

Shiraz-the capital city of Fars province in Southwest of Iran-is one of the largest cities in Iran that is in counter with high amounts of air pollution since last decades as a result of population growth, urbanization, and hence, increased traffic-related air pollution. Besides, the high influxes of air pollutants in last decade through dust storms, well known as Middle Eastern Dust (MED) events, have deteriorated the welkin dramatically. Here, the authors aimed to assess the health impacts of short-term exposure to air pollutants in Shiraz city in a two-part study from 2008 to 2010 .

\section{Biomed Central}




\section{Materials and methods}

This study was conducted in two parts in Shiraz city of Iran-parts I and II. In part I, local relative risks (RRs) and baseline incidences (BIs) were calculate. In part II, calculation and comparison of number of the excess cardiovascular and respiratory hospitalizations because of exposure to air pollutants were done first by using existed default relative risk (RR) and baseline incidence (BI) of the air quality health impact assessment software AirQ 2.2.3, which is proposed approach by World Health Organization (WHO) for HIA [17]; and second by calculated RR and BI of part I or by applying a combination of these RRs and BIs in AirQ model.

\section{Part I: calculation of local RRs and BIs}

In this part, associations of exposure to air pollutants and hospitalizations due to cardiovascular and respiratory causes were examined in Shiraz city as the target population from 2008 to 2010 .

\section{Study area and demographic parameters}

Shiraz is the capital city of Fars Province in Southwest of Iran (Figure 1). It is located in the latitude of $29^{\circ} 36^{\prime} \mathrm{N}$ and the longitude of $52^{\circ} 32^{\prime} \mathrm{E}$ with average elevation of $1500 \mathrm{~m}$ above sea level. According to the latest census report by Statistical Centre of Iran (SCI) in 2005, the population is 1,2 million people, which this number has been estimated to increase to 1,3 million people in 2010 . The population of people older than 65 years old is about 85913. Meanwhile, Shiraz has a population growth rate of $1.3 \%$ based on the estimates of SCI [18].

\section{Air pollution data}

At the time of conducting this study there were two fixed air pollution monitors belonged to the Fars's Department of Environment (F-DOE) (Figure 1). Hourly air pollution data including particulate matter with aerodynamic diameter less than $10 \mu \mathrm{m}\left(\mathrm{PM}_{10}\right)$, sulfur dioxide $\left(\mathrm{SO}_{2}\right)$, and nitrogen dioxide $\left(\mathrm{NO}_{2}\right)$ obtained from $\mathrm{F}$ DOE. Thereafter, 24-hour means were calculated for each pollutant.

\section{Morbidity cases and classification}

The numbers of daily hospitalizations due to cardiovascular and respiratory causes were obtained from Medical Records Departments (MRD) of Shiraz hospitals. The MRDs of Shiraz hospitals provided morbidity cases in line with taxonomy of the International Classification of Diseases (ICD-10). According to the ICD-10, I00 to I99 and J00 to J99 codes have been defined for cardiovascular and respiratory diseases, respectively [19].

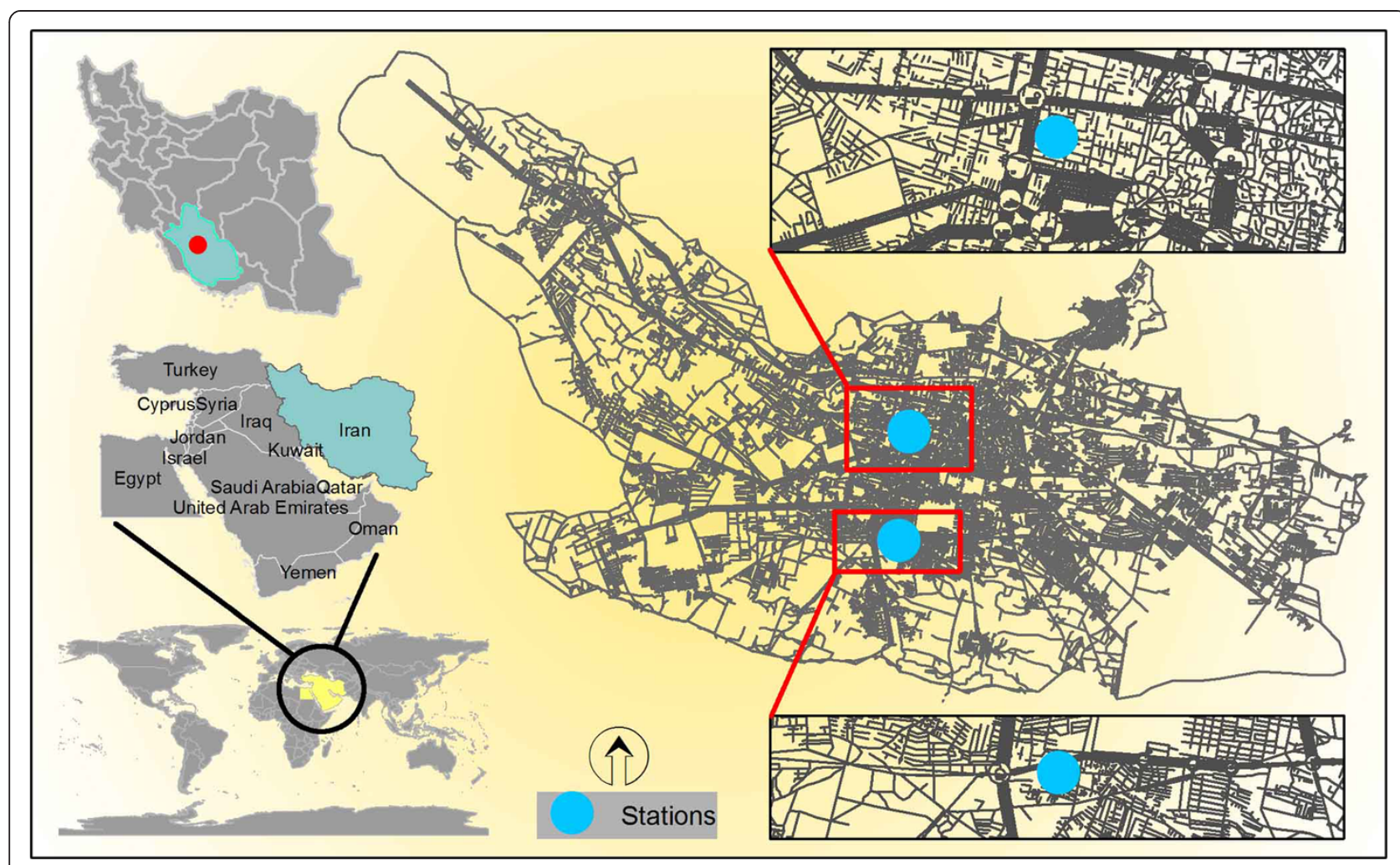

Figure 1 The study area of Shiraz, Iran and location of the air quality monitoring stations. 


\section{Correlation evaluation and RR calculation}

Correlation evaluation and RR calculation were done by applying Poisson regression with logarithmic link in generalized additive models (GAM). The GAM is expressed as the following equation [12]:

$$
\log [E(Y)]=\beta_{0}+\beta_{1} \times \text { pollutant }+S_{i}\left(X_{i}\right)+\cdots+S_{p}\left(X_{p}\right)
$$

Where $Y$ denotes the number of daily hospitalizations; $E(Y)$ denotes the number of expected cases; $X_{i}, i=1, \ldots, p$ which can be temperature, relative humidity, time, etc.; and $S_{i}, i=1, \ldots, p$ denotes smooth functions.

In order to analyze the data, first, quality of them were checked for missing data and errors using SPSS and Microsoft Office Excel, and resolved as possible. In this part of the study, the effects of meteorology variables including temperature and relative humidity; day of the week including working days, holidays, and days after holidays; and time were entered to the model as confounding factors and their effects were removed on number of hospitalizations using smooth function to calculate net effect of pollutant on the number of hospitalizations. In order to adjust the effect of those predictor variables in which affect response variable with lag of several days, smooth function was applied on auto regressive values. Finally, GAM models were fitted on the data using "mgcv" package in R statistical software [20,21].

\section{Part II: health impact assessment of air pollution}

The main aim of this part of the study was HIA of air pollution on the target population using AirQ 2.2.3 software. This software has been developed to estimate the health impacts of exposure to specific air pollutants on a resident population in a certain area and period. In this software, HIA of air pollutants is standing on calculation of attributable proportion (AP) in which AP is fraction of health consequences in a specific population that can be attributed to a specific air pollutant exposure with this notion that there is proven causative correlation between health consequences and air pollutant exposure [22,23]. The AP is calculated as the following equation [23]:

$$
A P=\frac{\Sigma\{[\operatorname{RR}(c)-1] \times P(c)\}}{\Sigma[\operatorname{RR}(c) \times P(c)]}
$$

Where RR denotes the relative risk for a given health endpoint, in category "c" of exposure, obtained from the concentration-response functions derived from wide literature (i.e., current existent epidemiological studies) and $P(c)$ denotes the proportion of the population in category "c" of exposure.

The rate attributable to the exposure can be calculated as the following equation if the baseline frequency of the health endpoint is known in the population:

$$
\mathrm{IE}=I \times \mathrm{AP}
$$

Where IE denotes the rate of the health outcome attributable to the exposure and $I$ denotes the baseline frequency of the health endpoint in the population.

Finally, the number of cases attributable to the exposure can be estimated as the following equation knowing the size of the population:

$$
\mathrm{NE}=\mathrm{IE} \times \mathrm{N}
$$

Where NE denotes the number of cases attributed to the exposure and $\mathrm{N}$ denotes the size of the population investigated.

In this research, air quality, health outcomes, and exposed population data were entered to the software for the period of 2008 to 2010. Moreover, estimation of the excess hospitalizations due to cardiovascular diseases, respiratory diseases, COPDs, and respiratory diseases in elderly group-people older than 65 years-old-as a result of short-term exposure to $\mathrm{PM}_{10}, \mathrm{SO}_{2}$, and $\mathrm{NO}_{2}$ were calculated using $\mathrm{RR}$ and $\mathrm{BI}$ of WHO, RR and BI of part I, RR of WHO and BI of part I, and RR of part I and BI of WHO for 2008, 2009, and 2010. It is noteworthy that the estimates of AirQ for different air pollutants should not be summed as it leads to overestimation (double counting) of some mortality/morbidity cases [24].

\section{Input adjustments}

HIA by AirQ needs concentration data of pollutants in $\mu \mathrm{g} / \mathrm{m}^{3}$ units. Thus, if the measurements of the monitors were reported in parts-per-million (ppm) or parts-perbillion (ppb) units, it would be necessary first to transform $\mathrm{ppm}$ or $\mathrm{ppb}$ to $\mu \mathrm{g} / \mathrm{m}^{3}$ units. In this procedure, there would be some adjustments for pressure and temperature. Hence, the following equation was used to transform ppm to $\mu \mathrm{g} / \mathrm{m}^{3}$ units [25]:

$$
C\left(\frac{\mu g}{m^{3}}\right)=\frac{C(p p m) \times M W}{V} \times 1000
$$

Where $C$ denotes the concentration of gaseous composition, $M W$ denotes the relative molecular mass of gaseous composition, and $V$ denotes the volume of one mole of pure gas at standard temperature and pressure $\left(\mathrm{STP}-0^{\circ} \mathrm{C}\right.$ and 1 atmosphere).

We also made corrections for non-standard temperatures and pressures using Ideal Gas Equation:

$$
\frac{P_{1} V_{1}}{T_{1}}=\frac{P_{2} V_{2}}{T_{2}}
$$

Where $P_{1}, V_{1}$, and $T_{1}$ are the initial pressure, volume and absolute temperature and $P_{2}, V_{2}$, and $T_{2}$ are the final pressure, volume and absolute temperature. 


\section{Results}

\section{Results of part I}

Figure 2 shows descriptive statistics of air quality in Shiraz in 2008 to 2010. The maximum daily and annual mean $\mathrm{PM}_{10}$ concentrations in 2009 were 1024.4 and $111.3 \mu \mathrm{g} / \mathrm{m}^{3}$, respectively. In 2008, the annual mean concentration of $\mathrm{SO}_{2}$ was $674.9 \mu \mathrm{g} / \mathrm{m}^{3}$, which is much higher than daily means in 2009 and 2010. In addition, the maximum annual mean concentration of $\mathrm{NO}_{2}$ concentration was in 2010, which was $90.0 \mu \mathrm{g} / \mathrm{m}^{3}$.

In Table 1, calculated RR and BI of the part I with 95\% confidence interval $(\mathrm{CI})$ in $10 \mu \mathrm{g}$ increase of daily mean of $\mathrm{PM}_{10}, \mathrm{SO}_{2}$, and $\mathrm{NO}_{2}$ pollutants have been tabulated in relation with excess hospitalization cases due to cardiovascular diseases, respiratory diseases, respiratory diseases in elderly group, and COPDs. As can be seen in Table 1, no BI has been reported for respiratory diseases in elderly group so that calculation of excess cases due to short-term exposure to $\mathrm{SO}_{2}$ and $\mathrm{NO}_{2}$ pollutants have been calculated considering RR of WHO \& $\mathrm{BI}$ of part I; and RR \& BI of part I. According to the results of part I, association of $\mathrm{PM}_{10}$ and hospitalizations due to cardiovascular diseases was not significant $(p>0.05)$. However, there was a significant relationship between $\mathrm{PM}_{10}$ and hospitalizations due to respiratory diseases $(p=0.048)$. In addition, according to the findings of part I, there was significant association between $\mathrm{SO}_{2}$ and $\mathrm{NO}_{2}$ pollutants and hospitalizations due to respiratory diseases in elderly group and COPDs $(p<0.001)$.

\section{Results of part II}

In Table 2, the numbers of excess hospitalization cases due to cardiovascular and respiratory diseases as a result of short-term exposure to $\mathrm{PM}_{10}$ in 2008 to 2010 have been tabulated. As can be seen, the maximum number of excess hospitalizations due to cardiovascular and respiratory diseases is related to $\mathrm{RR}$ of $\mathrm{WHO}$ \& BI of part I; and RR \& BI of WHO, respectively. According to the results of this table, the maximum number of excess hospitalizations due to cardiovascular and respiratory diseases is because of short-term exposure to $\mathrm{PM}_{10}$ in 2009.

In Table 3, the numbers of excess hospitalizations due to respiratory diseases in elderly group and COPDs because of short-term exposure to $\mathrm{SO}_{2}$ have been calculated based on a combination of RR \& BI of WHO (default values). According to the results of this table, the maximum numbers of hospitalizations due to respiratory diseases are in elderly group and hospitalizations due to COPDs because of short-term exposure to $\mathrm{SO}_{2}$ in 2008 .

In Table 4, the number of excess hospitalizations due to respiratory diseases in elderly group and COPDs as a result of short-term exposure to $\mathrm{NO}_{2}$ have been calculated based on a combination of RR \& $\mathrm{BI}$ of WHO (default values). According to the results of this table, the maximum numbers of hospitalizations due to respiratory diseases are in elderly group and hospitalizations due to COPDs because of shortterm exposure to $\mathrm{NO}_{2}$ in 2010.

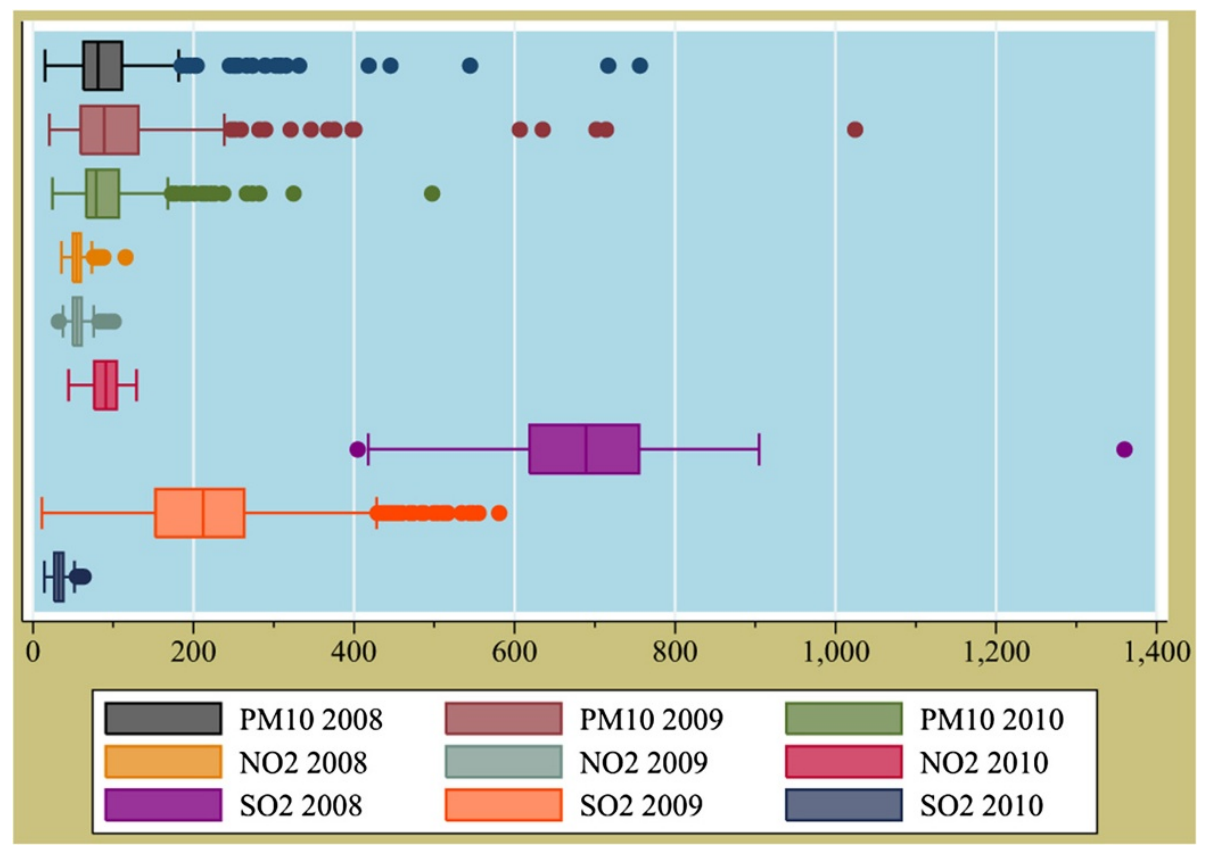

Figure 2 Annual concentrations of air pollutants $\left(\mu \mathrm{g} / \mathrm{m}^{3}\right)$ in Shiraz, Iran from 2008 to 2010. 
Table 1 Relative risks with $95 \%$ confidence interval for each $10 \mu \mathrm{g} / \mathrm{m}^{3}$ increase in daily mean concentrations of $\mathrm{PM}_{10}$, $\mathrm{SO}_{2}$, and $\mathrm{NO}_{2}$

\begin{tabular}{|c|c|c|c|c|c|c|c|c|}
\hline \multirow{3}{*}{ Health end point } & \multicolumn{2}{|c|}{$\mathrm{PM}_{10}$} & \multicolumn{2}{|c|}{$\mathrm{SO}_{2}$} & \multicolumn{2}{|c|}{$\mathrm{NO}_{2}$} & \multicolumn{2}{|c|}{ BI per 100000} \\
\hline & WHO RR & Part I RR & WHO RR & Part I RR & WHO RR & Part I RR & WHO & Part I \\
\hline & $(95 \% \mathrm{Cl})$ & $(95 \% \mathrm{Cl})$ & $(95 \% \mathrm{Cl})$ & $(95 \% \mathrm{Cl})$ & $(95 \% \mathrm{Cl})$ & $(95 \% \mathrm{Cl})$ & & \\
\hline \multirow{2}{*}{$\begin{array}{l}\text { Hospital admissions } \\
\text { due to CDs }\end{array}$} & 1.009 & 1.002 & $-*$ & - & - & - & 436 & 1447 \\
\hline & (1.006 to 1.013$)$ & (1.0001 to 1.0040$)$ & & & & & & \\
\hline \multirow{2}{*}{$\begin{array}{l}\text { Hospital admissions } \\
\text { due to RDs }\end{array}$} & 1.0080 & 1.0049 & - & - & - & - & 1260 & 849 \\
\hline & (1.0048 to 1.0112$)$ & (1.0004 to 1.0110$)$ & & & & & & \\
\hline \multirow{2}{*}{$\begin{array}{l}\text { Hospital admissions } \\
\text { due to RDsE** }\end{array}$} & - & - & 1.004 & 1.054 & 1.0038 & 1.028 & $-* * *$ & 61 \\
\hline & & & (1.001 to 1.009 ) & (1.005 to 1.120$)$ & (1.0000 to 1.0120$)$ & (1.011 to 1.045 ) & & \\
\hline \multirow{2}{*}{$\begin{array}{l}\text { Hospital admissions } \\
\text { due to COPDs }\end{array}$} & $-* * * *$ & - & 1.0044 & 1.095 & 1.0038 & 1.036 & 101.4 & 92 \\
\hline & & & (1.0000 to 1.0110$)$ & (1.070 to 1.110$)$ & (1.0004 to 1.0094$)$ & (1.021 to 1.051 ) & & \\
\hline
\end{tabular}

Abbreviations: $\mathrm{Bl}$ baseline incidence, $C D$ s cardiovascular diseases, $\mathrm{Cl}$ confidence interval, $C O P D$ s chronic obstructive pulmonary diseases, $\mathrm{NO}_{2}$ nitrogen dioxide, $P M_{10}$ particulate matter with aerodynamic diameter less than $10 \mu \mathrm{m}, R D s$ respiratory diseases, $R D s E$ respiratory diseases in elderly group (people older than 65 years-old), $R R$ relative risk, $\mathrm{SO}_{2}$ sulfur dioxide, $W H O$ World Health Organization.

*There are no RRs for cardiovascular and respiratory diseases due to short-term exposure to $\mathrm{SO}_{2}$ and $\mathrm{NO}_{2}$ in AirQ software so that they were not calculated in part I of the study.

** Based on classification of AirQ.

***The $\mathrm{BI}$ has not been presented in AirQ for respiratory diseases in elderly group.

**** There is no RR for COPDs due to short-term exposure to $\mathrm{PM}_{10}$ in AirQ so that it is not calculated in part I of the study.

\section{Discussion}

In this research, the authors tried to quantify effects of short-term exposure to specific air pollutants- $\mathrm{PM}_{10}$, $\mathrm{SO}_{2}$, and $\mathrm{NO}_{2}$ - on some health consequences including cardiovascular and respiratory diseases, such as COPDs, using AirQ model in different scenarios. In other words, we tried to estimate excess hospitalization cases due to cardiovascular diseases, respiratory diseases, respiratory diseases in elderly group, and COPDs due to short-term exposure to air pollutants. Noteworthy, estimation of number of excess hospitalizations due to respiratory diseases as a result of short-term exposure to $\mathrm{SO}_{2}$ and $\mathrm{NO}_{2}$ are categorized in three age-groups including $<15$, 15-65, and $\geq 65$ years-old. Notwithstanding, in this study-part I-categorization of patients was in two groups ( $<65$ and $\geq 65$ years-old). Thus, calculation of RR and BI for $\leq 15$ and 15-65 years-old age-groups was impossible so that calculation of RR, BI, and number of excess hospitalizations due to respiratory diseases was done for $\geq 65$ years-old age-group.
As illustrated in Figure 2, the annual mean concentration of $\mathrm{PM}_{10}$ in 2008 to 2010 has been 102.5, 111.3, and $92.1 \mu \mathrm{g} / \mathrm{m}^{3}$, respectively. Likewise, analyses of $\mathrm{PM}_{10}$ concentrations in 2008 to 2010 revealed occurrence of MED events, especially in 2009, which can affect results of Part I. With this in mind, indeed, AirQ software has been developed based on RRs of exposure to traffic-related air pollutants so that RRs of this software may not necessarily be applicable for HIA of MED events [24]. Meanwhile, the annual mean concentration of $\mathrm{SO}_{2}$ in 2008 to 2010 has been $674.8,209.4$, and $32.7 \mu \mathrm{g} / \mathrm{m}^{3}$, respectively, which shows a decreasing slope. This may be due to the decrease of sulfur in the fuel and/or increase of vehicles that use compressed natural gas (CNG) for gas up-albeit this point has been confirmed by F-DOE that those vehicles that use gasoline for gas up are responsible for $\mathrm{SO}_{2}$ pollution in Shiraz. In addition, the annual mean concentration of $\mathrm{NO}_{2}$ during the mentioned period has been 55.0, 55.8, and $90.0 \mu \mathrm{g} / \mathrm{m}^{3}$, respectively, which evidently is increased and supports the notion of increase in use of CNG instead

Table 2 Number of excess hospitalizations due to cardiovascular and respiratory diseases as a result of short-term exposure to $\mathrm{PM}_{10}$ in 2008 to 2010

\begin{tabular}{|c|c|c|c|c|c|}
\hline \multirow{2}{*}{ Year } & \multirow{2}{*}{ Health end point } & \multicolumn{4}{|c|}{ Number of excess cases } \\
\hline & & WHO RR \& BI & WHO RR \& Part I BI & Part I RR \& BI & Part I RR \& WHO BI \\
\hline \multirow[t]{2}{*}{2008} & Hospital admissions due to cardiovascular diseases & 419 & 1389 & 328 & 99 \\
\hline & Hospital admissions due to respiratory diseases & 1084 & 731 & 460 & 682 \\
\hline \multirow[t]{2}{*}{2009} & Hospital admissions due to cardiovascular diseases & 449 & 1489 & 353 & 106 \\
\hline & Hospital admissions due to respiratory diseases & 1163 & 783 & 494 & 733 \\
\hline \multirow[t]{2}{*}{2010} & Hospital admissions due to cardiovascular diseases & 388 & 1287 & 302 & 91 \\
\hline & Hospital admissions due to respiratory diseases & 1004 & 677 & 424 & 630 \\
\hline
\end{tabular}

Abbreviations: $W H O$ World Health Organization, $R R$ relative risk, $B I$ baseline incidence. 
Table 3 Number of excess hospitalizations due to respiratory diseases as a result of short-term exposure to $\mathrm{SO}_{2}$ in 2008 to 2010

\begin{tabular}{|c|c|c|c|c|c|}
\hline \multirow{2}{*}{ Year } & \multirow{2}{*}{ Health end point } & \multicolumn{4}{|c|}{ Number of excess cases } \\
\hline & & WHO RR \& BI & WHO RR \& Part I BI & Part I RR \& BI & Part I RR \& WHO BI \\
\hline \multirow{2}{*}{2008} & Hospital admissions due to RDsE & - & 110 & 520 & - \\
\hline & Hospital admissions due to COPDs & 198 & 180 & 900 & 992 \\
\hline \multirow{2}{*}{2009} & Hospital admissions due to RDsE & - & 60 & 410 & - \\
\hline & Hospital admissions due to COPDs & 108 & 98 & 776 & 855 \\
\hline \multirow{2}{*}{2010} & Hospital admissions due to RDsE & - & 7 & 137 & - \\
\hline & Hospital admissions due to COPDs & 13 & 12 & 208 & 229 \\
\hline
\end{tabular}

Abbreviations: WHO World Health Organization, $R R$ relative risk, $B I$ baseline incidence, $R D s E$ respiratory diseases in elderly group (people older than 65 years-old), COPDs chronic obstructive pulmonary diseases.

of gasoline since combustion of CNG produce more nitrogen oxides.

As shown in Table 1, the calculated BI per 100,000 people in part I of the study due to respiratory diseases, is $25 \%$ less than $\mathrm{BI}$ of $\mathrm{WHO}$ whilst this measure for cardiovascular diseases is 4.9 fold of WHO's BI. While these may be true, it is obvious that Shiraz is medical hub in Southwest of Iran and it hosts many patients from outside of the city. Since there were no adequate and accurate addresses for patients by MRDs of hospitals, all admissions were entered to the calculation of $\mathrm{BI}$, which this may be the reason for obtaining greater $\mathrm{BI}$ for part I rather than BI of WHO.

There is no BI value for hospitalizations due to respiratory diseases in $\geq 65$ years-old age-group as a result of short-term exposure to $\mathrm{SO}_{2}$ and $\mathrm{NO}_{2}$ in the AirQ software so that the number of excess hospitalization cases were calculated by a combination of WHO's RR, part I's RR, and BI of part I of the study.

HIA of air pollution in Shiraz city using AirQ software revealed that the share of admissions for cardiovascular diseases as a result of exposure to $\mathrm{PM}_{10}$ during 2008 to 2010 and considering to RR \& BI of WHO are 2.3\%, $2.1 \%$, and $1.5 \%$ out of all shares of admissions due to cardiovascular diseases, respectively. Meanwhile, the share of admissions for cardiovascular diseases as a result of exposure to $\mathrm{PM}_{10}$ during 2008 to 2010 and considering to RR \& BI of part I are $1.8 \%, 1.6 \%$, and $1.2 \%$ out of all shares of admissions due to cardiovascular diseases, respectively, which are lower than estimates by using WHO's RR \& BI. Furthermore, results revealed that the share of admissions for respiratory diseases as a result of exposure to $\mathrm{PM}_{10}$ during 2008 to 2010 and considering to RR \& BI of WHO are $19.0 \%, 15.6 \%$, and $10.8 \%$ out of all shares of admissions due to respiratory diseases, respectively. Also, the shares of admissions for respiratory diseases as a result of exposure to $\mathrm{PM}_{10}$ during 2008 to 2010 and considering to RR \& BI of part I are 8.1\%, $6.6 \%$, and $4.6 \%$ out of all shares of admissions due to respiratory diseases, respectively, and are lower than estimates by using WHO's RR and BI.

As tabulated in Table 2, in line with estimates, the maximum number of excess hospitalizations due to cardiovascular and respiratory diseases attributable to $\mathrm{PM}_{10}$ exposure have been occurred in 2009, which is due to high concentrations of $\mathrm{PM}_{10}$ during most times of the year. Indeed, it is important to note that albeit calculated RRs for increase in $10 \mu \mathrm{g} / \mathrm{m}^{3}$ of $\mathrm{PM}_{10}$ are small for individuals, there would be extensive impacts in general population when they have exposure with $\mathrm{PM}_{10}$.

The shares of admissions due to respiratory diseases in elderly group as a result of exposure to $\mathrm{SO}_{2}$ during 2008

Table 4 Number of excess hospitalizations due to respiratory diseases as a result of short-term exposure to $\mathrm{NO}_{2}$ in 2008 to 2010

\begin{tabular}{|c|c|c|c|c|c|}
\hline \multirow{2}{*}{ Year } & \multirow{2}{*}{ Health end point } & \multicolumn{4}{|c|}{ Number of excess cases } \\
\hline & & WHO RR \& BI & WHO RR \& Part I BI & Part I RR \& BI & Part I RR \& WHO BI \\
\hline \multirow[t]{2}{*}{2008} & Hospital admissions due to RDsE & - & 13 & 57 & - \\
\hline & Hospital admissions due to COPDs & 21 & 19 & 160 & 177 \\
\hline \multirow[t]{2}{*}{2009} & Hospital admissions due to RDsE & - & 13 & 89 & - \\
\hline & Hospital admissions due to COPDs & 22 & 20 & 166 & 183 \\
\hline \multirow[t]{2}{*}{2010} & Hospital admissions due to RDsE & - & 23 & 145 & - \\
\hline & Hospital admissions due to COPDs & 39 & 35 & 265 & 292 \\
\hline
\end{tabular}


to 2010 and considering to RR of WHO \& BI of part I are $6.4 \%, 2.7 \%$, and $0.3 \%$ out of all shares of admissions due to respiratory diseases in elderly group, respectively. Also, the shares of admissions due to respiratory diseases in elderly group as a result of exposure to $\mathrm{SO}_{2}$ during 2008 to 2010 and considering to RR \& BI of part I are $30.3 \%, 18.3 \%$, and $4.9 \%$ out of all shares of admissions due to respiratory diseases in elderly group, respectively.

The shares of admissions for COPDs as a result of exposure to $\mathrm{SO}_{2}$ during 2008 to 2010 and considering to RR and BI of WHO are $12.4 \%, 5.3 \%$, and $0.5 \%$ out of all shares of admissions due to COPDs, respectively. Also, the share of admissions for COPDs as a result of exposure to $\mathrm{SO}_{2}$ during 2008 to 2010 and considering to RR \& BI of part I are $56.2 \%, 37.8 \%$, and $8.3 \%$ out of all shares of admissions due to COPDs, respectively. In fact, various factors, such as smoking, occupational exposures, inappropriate diet, indoor air pollution, exposure to $\mathrm{NO}_{2}$ and particulate matters can influence incidence of COPDs and RDs, especially in elderly people, but exposure to air pollutants can exacerbate these diseases as predisposing factors [26-34].

The share of admissions due to respiratory diseases in elderly group as a result of exposure to $\mathrm{NO}_{2}$ during 2008 to 2010 and considering to RR of WHO \& BI of part I are $0.8 \%, 0.6 \%$, and $0.8 \%$ out of all shares of admissions due to respiratory diseases in elderly group, respectively. Also, the shares of admissions due to respiratory diseases in elderly group as a result of exposure to $\mathrm{NO}_{2}$ during 2008 to 2010 and considering to RR \& BI of part I are $3.3 \%, 4.0 \%$, and $5.2 \%$ out of all shares of admissions due to respiratory diseases in elderly group, respectively.

The shares of admissions due to COPDs as a result of exposure to $\mathrm{NO}_{2}$ during 2008 to 2010 and considering to RR of WHO and BI of part I are $1.3 \%, 1.1 \%$, and $1.6 \%$ out of all shares of admissions due to COPDs, respectively. Also, the shares of admissions due to COPDs as a result of exposure to $\mathrm{NO}_{2}$ during 2008 to 2010 and considering to RR \& BI of part I are $10.0 \%, 8.1 \%$, and $10.6 \%$ out of all shares of admissions due to COPDs, respectively.

As tabulated in Tables 1, 2, 3, and 4, combination of RRs and BIs of WHO and part I give different results. There is no doubt, by all means, that the number of hospitalizations would decrease by abatement of air pollutants concentrations, even in using combinations of all RRs and BIs.

Many researchers, worldwide, have used the AirQ model. The majority of them, however, have focused on short-term effects of air pollutants on mortality due to cardiovascular and respiratory diseases [5,23,35-37]. For instance, Naddafi et al. (2012) have estimated that shortterm exposure to air pollutants including $\mathrm{PM}_{10}, \mathrm{SO}_{2}$,
$\mathrm{NO}_{2}$, and $\mathrm{O}_{3}$ in Tehran caused 2194, 1458, 1050, and 819 excess total mortality cases, respectively [5].

\section{Conclusions}

This study was the first attempt to assess health impacts of air pollution in Shiraz, Iran. Although the results of this study are in line with results of other researches around the world, since the geographic, demographic, and climate characteristics are different, there is still high need to further studies to specify local RRs and BIs. As mentioned above, air quality affects daily hospital admissions dramatically. Accordingly, cost-effective measures and management schemes should be considered to abate air pollution concentrations and/or reduce exposure of general population to air pollutants.

\section{Abbreviations}

AP: Attributable proportion; BI: Baseline incidence; COPDs: Chronic obstructive pulmonary diseases; Cl: Confidence interval; GAMs: Generalized additive models; HIA: Health impact assessment; ICD: International classification of diseases; $\mathrm{NO}_{2}$ : Nitrogen dioxide; $\mathrm{PM}_{10}$ : Particulate matter with aerodynamic diameter less than $10 \mu \mathrm{m}$; RR: Relative risk; $\mathrm{SO}_{2}$ : Sulfur dioxide; WHO: World Health Organization.

\section{Competing interests}

The authors declare they have no potential or actual competing financial or personal interests.

\section{Authors' contributions}

$M Y, A H M$, and RN participated in the design of the study and supervised the work. EG, HA, AAA, MS, and MY participated in the design of the study, and/ or statistical analyses, and/or interpreted the analyzed results. HA and EG wrote the first draft. AAA, MS, and MY revised the paper critically for important intellectual content. All authors have read and approved the final manuscript.

\section{Acknowledgments}

This research was part of the MSPH thesis of the first author and has been supported by Tehran University of Medical Sciences. The authors acknowledge Fars's Department of Environment for providing air pollution data. We would like to also thank Medical Records Departments of Shiraz hospitals for their wholehearted help.

\section{Author details}

${ }^{1}$ Department of Environmental Health Engineering, School of Public Health, Tehran University of Medical Sciences, Tehran, Iran. ${ }^{2}$ Institute for Environmental Research (IER), Tehran University of Medical Sciences, Tehran, Iran. ${ }^{3}$ Kurdistan Environmental Health Research Center, Kurdistan University of Medical Sciences, Sanandaj, Iran. ${ }^{4}$ Department of Epidemiology and Biostatistics, School of Public Health, Tehran University of Medical Sciences, Tehran, Iran. ${ }^{5}$ Department of Epidemiology and Reproductive Health, Reproductive Epidemiology Research Center, Royan Institute, ACECR, Tehran, Iran. ${ }^{6}$ Occupational Sleep Research Center, Tehran University of Medical Sciences, Tehran, Iran. ${ }^{7}$ Center for Air Pollution Research (CAPR), Institute for Environmental Research (IER), Tehran University of Medical Sciences, Tehran, Iran.

Received: 28 November 2012 Accepted: 3 June 2013

Published: 28 June 2013

\section{References}

1. Murray CJL, Lopez AD: Alternative projections of mortality and disability by cause 1990-2020: global burden of disease study. Lancet 1997, 349:1498-1504.

2. Cohen AJ, Anderson HR, Ostro B, Pandey KD, Krzyzanowski M, Künzli N, Gutschmidt K, Pope A, Romieu I, Samet JM: The global burden of disease 
due to outdoor air pollution. J Toxicol Environ Health A 2005, 68:1301-1307.

3. Brook RD, Rajagopalan S, Pope CA III, Brook JR, Bhatnagar A, Diez-Roux AV, Holguin F, Hong Y, Luepker RV, Mittleman MA: Particulate matter air pollution and cardiovascular disease. Circulation 2010, 121:2331-2378.

4. Schwartz J: Air pollution and daily mortality: a review and meta analysis. Environ Res 1994, 64:36-52.

5. Naddafi K, Hassanvand MS, Yunesian M, Momeniha F, Nabizadeh R, Faridi S, Gholampour A: Health impact assessment of air pollution in megacity of Tehran, Iran. Iran J Environ Health Sci \& Eng 2012, 9:1-7.

6. Qorbani M, Yunesian M, Fotouhi A, Zeraati H, Sadeghian S: Effect of air pollution on onset of acute coronary syndrome in susceptible subgroups. East Mediterr Health J 2012, 18:550-555.

7. Dominici F, Peng RD, Bell ML, Pham L, McDermott A, Zeger SL, Samet JM: Fine particulate air pollution and hospital admission for cardiovascular and respiratory diseases. JAMA 2006, 295:1127-1134.

8. Hosseinpoor AR, Forouzanfar MH, Yunesian M, Asghari F, Naieni KH, Farhood D: Air pollution and hospitalization due to angina pectoris in Tehran, Iran: a time-series study. Environ Res 2005, 99:126-131.

9. Hoek G, Brunekreef B, Fischer P, van Wijnen J: The association between air pollution and heart failure, arrhythmia, embolism, thrombosis, and other cardiovascular causes of death in a time series study. Epidemiology 2001, 12:355.

10. Garcia-Aymerich J, Tobias A, Anto JM, Sunyer J: Air pollution and mortality in a cohort of patients with chronic obstructive pulmonary disease: a time series analysis. J Epidemiol Community Health 2000, 54:73-74.

11. Katsouyanni K, Touloumi G, Spix C, Schwartz J, Balducci F, Medina S, Rossi G, Wojtyniak B, Sunyer J, Bacharova L: Short term effects of ambient sulphur dioxide and particulate matter on mortality in 12 European cities: results from time series data from the APHEA project. Br Med J 1997, 314:1658.

12. Schwartz J: Air pollution and hospital admissions for heart disease in eight U.S. counties. Epidemiology 1999, 10:17-22.

13. Schwartz J: Short term fluctuations in air pollution and hospital admissions of the elderly for respiratory disease. Thorax 1995, 50:531-538.

14. Schwartz J: Air pollution and hospital admissions for cardiovascular disease in Tucson. Epidemiology 1997, 8:371-377.

15. Pope CA, Thun MJ, Namboodiri MM, Dockery DW, Evans JS, Speizer FE, Heath CW Jr: Particulate air pollution as a predictor of mortality in a prospective study of US adults. Am J Respir Crit Care Med 1995, 151:669-674.

16. Dockery DW, Pope CA, Xu X, Spengler JD, Ware JH, Fay ME, Ferris BG Jr, Speizer FE: An association between air pollution and mortality in six US cities. N Engl J Med 1993, 329:1753-1759.

17. WHO European Centre for Environment and Health - Bilthoven Division: The air quality health impact assessment software AirQ 2.2.3.

18. Estimated population of country cities for 2011; 2011. Available via: http://www.amar.org.ir.

19. World Health Organization: International classification of diseases (ICD). Geneva, Switzerland; 2012. Available via: http://apps.who.int/classifications/ icd10/browse/2010/en.

20. Wood SN: Fast stable restricted maximum likelihood and marginal likelihood estimation of semi parametric generalized linear models. J R Stat Soc Series B Stat Methodol 2011, 73:3-36.

21. Venables W, Smith D: The R development core team (2004), an introduction to R. The R Development Core Team 2010, 2:1-90.

22. Krzyzanowski M: Methods for assessing the extent of exposure and effects of air pollution. Occup Environ Med 1997, 54:145-151.

23. Fattore E, Paiano V, Borgini A, Tittarelli A, Bertoldi M, Crosignani P, Fanelli R: Human health risk in relation to air quality in two municipalities in an industrialized area of Northern Italy. Environ Res 2011, 111:1321-1327.

24. Hassanvand $M, A$ mini $H$, Yunesian $M$ : Comments on: the evaluation of $\mathrm{PM}_{10}, \mathrm{PM}_{2.5}$, And $\mathrm{PM}_{1}$ concentrations during the middle eastern dust (MED) events in Ahvaz, Iran, from April through September 2010 (http://dx.doi.org/10.1016/j.Jaridenv.2011.09.007). Journal of Arid Environments 2013, 97:1-2. http://dx.doi.org/10.1016/j.jaridenv.2013.05.001.

25. Colls J: Air Pollution. 2nd edition. London and New York: Spon Press; 2002

26. Tehrani SM, Karbassi AR: Application of E-commerce in local home shopping and its consequences on energy consumption and air pollution reduction. Iran J Environ Health Sci \& Eng 2005, 2:247-250.

27. Schikowski T, Ranft U, Sugiri D, Vierkotter A, Bruning T, Harth V, Kramer U: Decline in air pollution and change in prevalence in respiratory symptoms and chronic obstructive pulmonary disease in elderly women. Respir Res 2010, 11:113.

28. Viegi G, Maio S, Pistelli F, Baldacci S, Carrozzi L: Epidemiology of chronic obstructive pulmonary disease: health effects of air pollution. Respirology 2006, 11:523-532.

29. Arbex MA, de Souza Conceicao GM, Cendon SP, Arbex FF, Lopes AC, Moyses EP, Santiago SL, Saldiva PH, Pereira LA, Braga AL: Urban air pollution and chronic obstructive pulmonary disease-related emergency department visits. J Epidemiol Community Health 2009, 63:777-783.

30. Naddafi K, Nabizadeh R, Soltanianzadeh Z, Ehrampoosh M: Evaluation of dust fall in the Air of Yazd. Iran J Environ Health Sci \& Eng 2006, 3:161-168.

31. Brauer M, Ebelt ST, Fisher TV, Brumm J, Petkau AJ, Vedal S: Exposure of chronic obstructive pulmonary disease patients to particles: respiratory and cardiovascular health effects. J Expo Anal Environ Epidemiol 2001, 11:490.

32. Brauer M, Hoek G, Smit H, De Jongste J, Gerritsen J, Postma DS, Kerkhof M, Brunekreef B: Air pollution and development of asthma, allergy and infections in a birth cohort. Eur Respir J 2007, 29:879-888.

33. Brauer M, Hoek G, Van Vliet P, Meliefste K, Fischer PH, Wijga A, Koopman LP, Neijens HJ, Gerritsen J, Kerkhof M: Air pollution from traffic and the development of respiratory infections and asthmatic and allergic symptoms in children. Am J Respir Crit Care Med 2002, 166:1092-1098.

34. Qorbani M, Yunesian M: Solid fuel smoke exposure and risk of obstructive airways disease. Iran J Environ Health Sci \& Eng 2012, 9:8.

35. Shakour A, El-Shahat M, El-Taieb N, Hassanein M, Mohamed A: Health impacts of particulate matter in greater Cairo, Egypt. J Am Sci 2011, 7:840-848.

36. Tominz R, Mazzoleni B, Daris F: Estimate of potential health benefits of the reduction of air pollution with $\mathrm{PM}_{10}$ in Trieste, Italy. Epidemiol Prev 2005, 29:149-155.

37. Boldo E, Medina S, LeTertre A, Hurley F, Mucke HG, Ballester F, Aguilera I, Eilstein D: Apheis: health impact assessment of long-term exposure to $\mathrm{PM}_{2.5}$ in 23 European cities. Eur J Epidemiol 2006, 21:449-458.

doi:10.1186/2052-336X-11-11

Cite this article as: Gharehchahi et al:: Health impact assessment of air pollution in Shiraz, Iran: a two-part study. Journal of Environmental Health Sciences \& Engineering 2013 11:11.

\section{Submit your next manuscript to BioMed Central and take full advantage of:}

- Convenient online submission

- Thorough peer review

- No space constraints or color figure charges

- Immediate publication on acceptance

- Inclusion in PubMed, CAS, Scopus and Google Scholar

- Research which is freely available for redistribution

Submit your manuscript at www.biomedcentral.com/submit
C) Biomed Central 